\title{
ENT morbidity at high altitude
}

\author{
B K PRASAD \\ Department of ENT and Head and Neck Surgery, Command Hospital (Eastern Command (EC)), Kolkata, \\ West Bengal, India
}

\begin{abstract}
Background: People suffer unique health problems in high altitude areas, due to such factors as elevation, aircraft ascent and descent, extreme cold, hypoxia, hypobaria, and low relative humidity. This study was conducted to evaluate ENT morbidity at high altitude.

Methods: Serving soldiers introduced to a high altitude environment who presented with various ENT symptoms were examined to identify ENT disease. In addition, patients undergoing hyperbaric chamber therapy, tracheostomy and treatment of cold injuries were also examined for ENT problems.

Results: The following were detected: 13 cases of otic barotrauma, 11 cases of sinus barotrauma, three cases of vertigo, six cases of pinna frostbite, three cases of barotrauma caused by hyperbaric chamber therapy, an unusually high incidence of epistaxis, and innumerable patients with high altitude pharyngitis.

Conclusion: Diseases of the ear, nose and throat contribute significantly to high altitude morbidity. In a military context, health education of troops is necessary to avoid such problems.
\end{abstract}

Key words: Altitude; Head and Neck; Barotrauma; Frostbite

\section{Introduction}

By definition, any location which is $2700 \mathrm{~m}$ (9000 feet) or more above sea level is considered to be at high altitude. Many health problems hamper healthy human life at such elevations. However, the scientific literature lacks information on ENT morbidity associated with high altitudes.

This article presents a personal experience of ENT problems encountered at the highest multi-specialty hospital in the world, located at an altitude of $3600 \mathrm{~m}$.

The atmospheric pressure at sea level is 1 Atmosphere. Above sea level, the atmospheric pressure decreases by 50 per cent for every increase of approximately $5400 \mathrm{~m} .{ }^{1}$ Thus, air has a lower density at high altitude because its component gases expand.

The response of gas to pressure changes also governs the behaviour of air in the middle ear and paranasal sinuses. During ascent, gas in the middle ear expands, whereas during descent the volume of gas decreases as the atmospheric pressure increases. During descent, the eustachian tube must be opened by swallowing movements to enable the middle-ear volume to be adjusted. If this mechanism fails or is delayed, increasing differential pressure acting on the soft nasopharyngeal end of the eustachian tube will close it. When this pressure becomes greater than that which can be generated by the tubal dilator muscles, the eustachian tube becomes 'locked'. Thereafter, assuming descent continues, the pathological changes of otic barotrauma are inevitable. These changes affect the tympanic membrane and middle ear and are mainly vascular. They manifest clinically as tympanic membrane invagination, congestion along the handle of the malleus and in the attic, interstitial haemorrhage, middle-ear effusion, and tympanic membrane rupture. ${ }^{2}$

During descent, forceful coughing and sneezing, or production of an overpressure in the middle ear via performing the Valsalva manoeuvre, may cause sudden pressure transfer into the inner ear, causing inner-ear barotrauma.

Sinus barotrauma during descent is caused by obstruction of the ostium from the nasal side. If obstruction remains unrelieved and descent continues, the decreasing volume of air in the sinus exerts a suction effect on the lining mucosa, thus increasing ostium blockage. During ascent, the ostium may be blocked from within the sinus cavity. Symptoms are produced by unrelieved expansion of air contained in the closed bony sinus. ${ }^{3}$

The present study was conducted in the north Indian region of Ladakh, situated at high altitude in the state of Jammu and Kashmir. Ladakh shares its geographical boundary with Pakistan in the west and China in the east. The climate is extremely cold and dry, and the 
terrain lacks vegetation. Such extreme weather causes severe crusting of the upper airway mucosa. This leads to an unusually high incidence of epistaxis and pharyngitis, tracheostomy problems, and chilblain and frostbite of the nose and pinna.

\section{Materials and methods}

The present study was carried out from September 2005 to January 2008 in a garrison hospital located $3600 \mathrm{~m}$ above sea level. The ENT department evaluated deployed soldiers operating in various high altitude locations, from sparsely vegetated areas at $2700 \mathrm{~m}$ and cold deserts at $3000-4500 \mathrm{~m}$ to the icy heights of the Siachen glacier at $6900 \mathrm{~m}$. All patients were male, of various ages. All soldiers had been medically examined prior to their induction into high altitude work and had been declared medically fit. Patients included soldiers new to high altitude service, those who had remained in the area for up to two years, and those returning to the area after lower altitude service.

Thirteen cases of otic barotrauma and 11 cases of sinus barotrauma were diagnosed. These cases were analysed for their presenting symptoms, clinical signs and predisposing factors. Treatment aimed to relieve pain and to maintain the ventilation of the middle ear and paranasal sinuses. Surgery was reserved for underlying nasal pathology and non-healing tympanic membrane perforations.

Three cases of sudden-onset vertigo during descent from altitude were evaluated. Otological monitoring comprised otoneurological testing and pure tone audiometry.

Twelve cases of high altitude cerebral oedema and nine cases of high altitude pulmonary oedema were treated in a hyperbaric chamber. As a precautionary measure, these patients were asked to evacuate their bladder and bowel and were taught the Valsalva manoeuvre. Nasal decongestant drops were instilled into the nose, drinking water was available inside the hyperbaric chamber to assist swallowing, and a nursing assistant stayed inside the chamber to monitor the patient's vital signs and oxygen saturation. The chamber was pressurised with air, and patients were given 100 per cent, pressurised oxygen via a face mask.

A total of 262 cases of epistaxis were evaluated with nasal endoscopic examination to determine their aetiology.

Forty-two cases of frostbite and 36 cases of chilblain were examined for head and neck involvement.

A large number of cases of chronic cough were seen in the hospital out-patient department. A careful clinical history excluded smoking, chronic infection, gastroesophageal reflux disease, angiotensin-converting enzyme medication, etc. Local causes in the throat were excluded by oropharyngeal examination and flexible fibre-optic laryngoscopy.

\section{Results and analysis}

\section{Otic barotrauma}

All 13 cases of otic barotrauma had no history of previous aural disease. Three patients were new to high altitude service, whereas 10 had returned to high altitude service after low altitude work. Nine cases were unilateral and four bilateral. All presented with acute earache, while six also complained of upper respiratory tract infection symptoms. Only three patients had tympanic membrane perforation on otoscopic examination at presentation (Table I).

The majority of patients recovered with conservative treatment (Table II). All 13 cases had identifiable predisposing factors. Surgery was undertaken to treat the underlying nasal causes in six cases, to drain middleear effusion in one case and to repair tympanic membrane perforation in another. One patient was lost to follow up (Table III).

\section{Sinus barotrauma}

Of the 11 cases of sinus barotrauma, nine were unilateral and two bilateral. Two patients presented with frontal headache only. Nine patients had facial pain. All patients were assessed for predisposing factors, and most were treated surgically (Table IV).

\section{Vertigo}

Three patients, all new to high altitude service, presented immediately upon arrival with acute-onset vertigo with no other aural symptoms. None of the three patients had nystagmus, and the fistula sign was negative. They were managed conservatively with bed rest, vasodilators, laxatives and otological monitoring. Clinical features resolved in three days.

\section{Barotruma related to hyperbaric chamber therapy}

Of the 21 patients treated in the hyperbaric chamber, three (14 per cent) suffered otic barotrauma.

\section{Frostbite}

Of the 78 cases of cold injury, six were found to have frostbite of the pinna. Both ears were affected in two cases. Prolonged contact of the pinna with the flaps of a wet cap was found to be the cause in all cases. Patients were treated with rapid re-warming in water heated to $40-42^{\circ} \mathrm{C}$, aloe vera cream application, oral

\begin{tabular}{|c|c|}
\hline \multicolumn{2}{|c|}{$\begin{array}{c}\text { TABLE I } \\
\text { OTIC BAROTRAUMA CASES: OTOSCOPIC FINDINGS } \\
\text { ON PRESENTATION* }\end{array}$} \\
\hline Findings & Pts $(n)$ \\
\hline Unilat retracted, congested TM & 8 \\
\hline Bilat retracted, congested TM & 2 \\
\hline Perf R TM + retracted, congested L TM & 2 \\
\hline Multiple TM perfs & 1 \\
\hline
\end{tabular}

${ }^{*}$ Within 24 hours of arrival. Pts = patients; unilat $=$ unilateral; $\mathrm{TM}=$ tympanic membrane; bilat $=$ bilateral; perf $=$ perforation; $\mathrm{R}=$ right; $\mathrm{L}=$ left 


\begin{tabular}{|c|c|}
\hline $\begin{array}{r}\text { TABLE I } \\
\text { OTIC BAROTRAUMA PATIENTS } \\
\text { AFTER MEDICAL TI }\end{array}$ & DINGS \\
\hline Findings & Pts $(n)$ \\
\hline Recovered* & 7 \\
\hline Progression to $\mathrm{OME}$ & 3 \\
\hline Persistent OME with conductive $\mathrm{HL}$ & 1 \\
\hline Persistent bilat TM perf $f^{\dagger}$ & 1 \\
\hline Multiple R TM perfs & 1 \\
\hline $\begin{array}{l}\text { *Following active coryza treatment. } \\
\text { membrane (TM) healed after four w } \\
\text { otitis media with effusion; HL }=\text { h } \\
\text { perf = perforation; } \mathrm{R}=\text { right }\end{array}$ & $\begin{array}{l}\text { Impanic } \\
\text { OME = } \\
\text { ilateral; }\end{array}$ \\
\hline
\end{tabular}

pentoxyphyllin $400 \mathrm{mg}$ twice daily and oral aspirin $150 \mathrm{mg}$ once daily.

\section{High altitude pharyngitis}

Sore throat and chronic cough were found to be nearly universal in any personnel who had spent some time at high altitude. These symptoms occurred without fever, chills, myalgia, lymphadenopathy, exudate, gastroesophageal reflux or any sign of infection.

\section{Epistaxis}

Of the 262 cases of epistaxis (comprising 8.7 per cent of total out-patient department attendance), 107 (41 per cent) were caused by nasal crusts and their dislodgement - a significant proportion (Table V). Commonly affected sites were Little's area, the septal spur and the anterior end of the inferior turbinate. All active bleeding was treated by chemical cautery.

\section{Discussion}

\section{Otic barotrauma}

The development of otic barotrauma is dependent upon the rate of descent or the rate of ambient pressure increase, in contrast to the rate of middle-ear pressure increase. The latter is affected by the patency of the lumen and by the degree, frequency and duration of eustachian tube opening. ${ }^{4}$ One episode of otic barotrauma can predispose an individual to further episodes, if the original predisposing factor persists, or if

\begin{tabular}{|c|c|c|}
\hline \multicolumn{3}{|c|}{$\begin{array}{c}\text { TABLE III } \\
\text { OTIC BAROTRAUMA PATIENTS: PREDISPOSING } \\
\text { FACTORS AND TREATMENT }\end{array}$} \\
\hline $\begin{array}{l}\text { Predisposing } \\
\text { factor }\end{array}$ & $\begin{array}{l}\text { Pts } \\
(n)\end{array}$ & Treatment \\
\hline Coryza & 7 & Conservative \\
\hline DNS & 3 & Septoplasty \\
\hline Sinusitis & 1 & $\begin{array}{l}\text { FESS } \\
\text { Later myringotomy \& grommets }\end{array}$ \\
\hline Allergic rhinitis & 1 & $\begin{array}{l}\text { Topical nasal steroid spray } \\
\text { Myringoplasty* }\end{array}$ \\
\hline Allergic rhinitis & 1 & Lost to follow up ${ }^{\dagger}$ \\
\hline
\end{tabular}

* Successful. ${ }^{\dagger}$ Patient had multiple right tympanic membrane perforations. Pts = patients; DNS = deviated nasal septal; FESS = functional endoscopic sinus surgery

\begin{tabular}{lcc}
\multicolumn{3}{c}{ TABLE IV } \\
\multicolumn{3}{c}{$\begin{array}{c}\text { SINUS BAROTRAUMA PATIENTS: PREDISPOSING } \\
\text { FACTORS AND TREATMENT }\end{array}$} \\
\hline Predisposing factor & Pts $(n)$ & \multicolumn{1}{c}{ Treatment } \\
\hline Coryza with DNS & 4 & Septoplasty \\
Sinusitis with DNS & 4 & Septoplasty \& FESS \\
Allergic rhinitis & 1 & Topical steroid spray \\
Allergic rhinitis & 2 & FESS \& topical steroid spray \\
with polyps & & \\
\hline \multicolumn{2}{l}{ Pts = patients; DNS = deviated nasal septum; FESS = functional } \\
endoscopic sinus surgery
\end{tabular}

sufficient time has not been allowed for the original lesion to recover before the individual is exposed to further pressure changes. ${ }^{5}$

\section{Sinus barotrauma}

Humans can voluntarily control the ostium of the eustachian tube by swallowing, yawning, gaping, or performing the Valsalva or Frenzel manoeuvre, but have no such control over the ostia of sinuses. Sinus ostia may be occluded by a plug of mucus, mucosal oedema, polyp or mass. This obstruction is often valvular in nature, so that air passes easily in one direction only. Coryza, vasomotor rhinitis, allergic rhinitis and rhinosinusitis can also cause oedema of the nasal mucosa, which predisposes to sinus barotrauma. Nasal trauma and nasal septum deviations can also act in the same way.

Described in aviators by King in 1965, sinus barotrauma most commonly involves the frontal sinus. ${ }^{6}$ In Fagan and colleagues' series of affected patients, there was a prior history of previous paranasal sinus barotrauma in one-third, and a history of recent upper respiratory tract infection or chronic nasal and sinus inflammatory disease in one-half. ${ }^{7}$ None of these cases required surgery.

\section{Inner-ear barotrauma}

Goodhill stated in 1971 that an increase in intracranial pressure from coughing, sneezing or straining may cause sudden, spontaneous rupture of the round

\begin{tabular}{lrc}
\multicolumn{3}{c}{ TABLE V } \\
EPISTAXIS PATIENTS: AETIOLOGY \\
\cline { 2 - 3 } Aetiology & \multicolumn{2}{c}{ Pts } \\
\cline { 2 - 3 } & $n$ & $\%$ \\
\hline Crusts & 107 & 41 \\
Infection & 78 & 80 \\
Trauma & 21 & 5 \\
Hypertension & 13 & 2 \\
Atrophic rhinitis & 6 & 0.8 \\
Tumour & 2 & 0.8 \\
Rhinosporidiosis & 2 & 12 \\
DIC & 1 & 100 \\
Idiopathic & 32 & \\
Total & 262 & \\
\hline
\end{tabular}

Pts $=$ patients $;$ DIC $=$ disseminated intravascular coagulation 
window. ${ }^{8}$ This same author also believed that a sudden change in middle-ear pressure may have the same effect during flight. Jones termed this 'pressure vertigo', and Lundgren 'alternobaric vertigo'.,, 10 Afflicted patients present with sudden deafness, tinnitus, and intense, short-lasting vertigo or ataxia. Otorhinolaryngological examination will reveal nystagmus and sensorineural hearing loss. Findings of decompression sickness, such as joint pain or central nervous system symptoms, will be conspicuously lacking.

It is postulated that this overpressure in the middle ear is not transmitted equally to the fluid system of the inner ear by the round and oval windows at the same time, and there may also be a mismatch between the left and the right ear.

However, in the present study none of the three vertigo cases had tinnitus or deafness. In the absence of nystagmus and the fistula sign, it was presumed that vertigo could have resulted from temporary vasospasm due to extremely cold weather.

\section{Hyperbaric chamber therapy}

At sea level, the atmospheric pressure is 1 Atmosphere; at $3600 \mathrm{~m}$ it is 0.6 Atmospheres. During hyperbaric chamber therapy, the rate of increase or decrease of pressure inside the chamber should not exceed 0.01 Atmospheres per minute. Therefore, in the present study it took 35 minutes to attain a pressure of 1 Atmosphere; this was then maintained for 6 hours. As patients breathe in oxygen under pressure, middleear ventilation is essential, otherwise otic barotrauma is inevitable.

Karhatay et al. assessed the development of otic barotrauma following hyperbaric chamber therapy, and reported a 66.7 per cent incidence, compared with incidences of 8-82 per cent published elsewhere. ${ }^{11}$ In the present study, 14 per cent of patients receiving hyperbaric chamber treatment developed otic barotrauma.

\section{Tracheostomy problems}

On the plains of India, the relative humidity varies between 60 and 99 per cent, whereas in Ladakh it ranges from 10 to 50 per cent, with an average of just 30 per cent. After tracheostomy, the tracheal mucosa has to be kept moist and humidified, otherwise there will be crusting, with the possibility of subsequent blockage and asphyxia. At high altitudes, saline nebulisation at frequent intervals keeps the respiratory tract moist, and early decannulation is advisable.

\section{Epistaxis}

Dry inspired air invariably causes crusting in the nose. As a result, epistaxis is a very common ENT problem at high altitude. Almost 100 per cent of the general population will experience minor nasal bleeding at some stage, but most will not seek ENT consultation. In Ladakh, as part of their health education, troops are advised to instil saline or glycerine nasal drops to keep the nasal mucosa moist and prevent crusting.

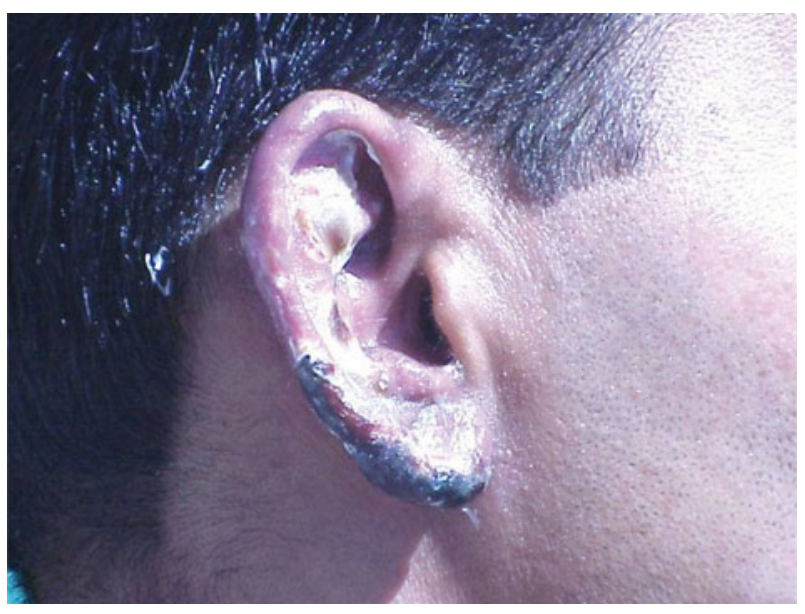

FIG. 1

Frostbite of the pinna.

\section{Cold injuries}

The present study included patients exposed to temperatures varying from -5 to $-50^{\circ} \mathrm{C}$. Cold injuries result from the inability to properly protect oneself from exposure to cold. These injuries can be of two types: (1) generalised (i.e. hypothermia) and (2) localised (i.e. chilblain and frostbite).

Chilblain comprises local swelling and tenderness after exposure to cold and moisture for 3-6 hours, and has little or no residual consequence. In contrast, frostbite involves the formation of ice crystals in tissues, along with denaturation of lipid-protein complexes, which may be followed by thrombosis, ischaemia and gangrene. The severity of frostbite depends on the temperature, length of exposure, wind chill factor and moisture level.

Cold injuries commonly affect the fingers and toes but can also affect the nose and ears. A common site in the head and neck region is the pinna (Figure 1).

\section{High altitude pharyngitis}

The term 'high altitude pharyngitis' is suggested because of the present study's finding of a high incidence of chronic cough in individuals living in a high altitude location, which could not be attributed to any

TABLE VI ENT MORBIDITY AT HIGH ALTITUDE: DISTRIBUTION*

\begin{tabular}{lc}
\hline Diagnosis & Pts $(n)$ \\
\hline High altitude pulmonary oedema & 91 \\
High altitude cerebral oedema & 12 \\
Acute mountain sickness & 113 \\
Frostbite & 42 \\
Chilblain & 36 \\
Deep vein thrombosis & 23 \\
Otic barotrauma & 13 \\
Sinus barotrauma & 11 \\
Vertigo & 3 \\
Epistaxis & 262 \\
\hline
\end{tabular}

*Patients treated September 2005 to January 2008. 
other cause. Hypoxia and hypobaria at high altitude demand extra breathing effort. The increase in ventilation forces obligate mouth-breathing, bypassing the warming and moisturising action of the nasal mucous membrane and sinuses. It is suggested that the movement of large amounts of cold, dry air across the pharyngeal mucosa causes marked dehydration, irritation and pain, similar to pharyngitis. Vasomotor rhinitis, which is quite common at cold temperatures, aggravates this condition by necessitating mouth-breathing during sleep.

- This study documented ENT morbidity in military personnel serving at high altitude

- Factors producing morbidity at high altitude include hypoxia, hypobaria, extreme cold, low humidity and hypercoagulability

- Particular ENT problems include frostbite, epistaxis, and barotrauma of the ear and sinuses

- Many high altitude ENT problems are preventable

Cases of high altitude pharyngitis were successfully treated by steam inhalation, forced hydration, throat lozenges and saline nasal drops.

\section{Conclusion}

Analysis of ENT morbidity encountered at high altitude reveals three types of disease: (1) life-threatening diseases such as high altitude pulmonary oedema, high altitude cerebral oedema and deep vein thrombosis; (2) limb-threatening diseases such as chilblain and frostbite; and (3) other diseases, including the ENT ailments detailed above (Table VI). Epistaxis is so common that it is accepted as part of life, until one suffers a severe case. Pharyngitis is bothersome but does not prevent soldiers from carrying out their duties. Barotrauma has not gained a place amongst the notifiable diseases of high altitude, not only because of less awareness of this problem, but also because the majority of cases go unreported. In Ladakh, the medical treatment given by Regimental
Medical Officers to soldiers suffering barotrauma is simple yet effective, and recovery is good with few residual consequences; hence, referral to an ENT specialist is infrequent.

These ENT problems are preventable if those at risk are aware. Hence, individuals living and working in high altitude areas should be educated about the possible ENT problems they face, and how to avoid them.

\section{References}

1 Farmer JC, Gillespie CA. Exposure to aerospace, diving and compressed gases. In: Alberti PW, Ruben RJ, eds. Otologic Medicine and Surgery. New York: Churchill Livingstone, 1988;2:1753-802

2 Edward C, Freeman P, Thomas R, Tonkin J, Blackwood FA. Otological Aspects of Diving. Sydney: Australian Medical Publishing, 1973

3 Benson AJ, King PF. Physiology of ear and nasal sinuses in the aerospace environment. In: Wright D, ed. Scott-Brown's Otolaryngology Basic Sciences, 5th edn. London: Butterworths, 1987;1:190-1

4 Dickson EDD, King PF. The Incidence of Barotraumas in Present Day Service Flying. Flying Personnel Research Committee Report No 881. London: Air Ministry, 1954

5 Miller GR Jr. ET function in normal and diseased ears. Arch Otolaryngol Head Neck Surg 1965;81:41-8

6 King PF. Sinus barotrauma. In: Gilles JA, ed. A Textbook of Aviation Physiology. London: Pergamon, 1965;112-21

7 Fagan P, Mckensie B, Edmonds C. Sinus barotraumas in divers. Ann Otol Rhinol Laryngol 1976;185:61-4

8 Goodhill V. Sudden deafness and round window rupture. Laryngoscope 1971;81:1462-74

9 Jones GM. Inner Ear Barotrauma in Service Flying. Flying Personnel Committee Report No 1021. London: Air Ministry, 1957

10 Lundgren CEG. Alternobaric vertigo - a diving hazard. BMJ 1965;2:511-13

11 Karhatay S, Yilmaz YF, Birkent H, Ay H, Satar B. Middle ear barotraumas with hyperbaric oxygen therapy: incidence and the predictive value of the nine step inflation/deflation test and otoscopy. Ear Nose Throat J 2008;87:684-8

Address for correspondence:

Lt Col (Dr) B K Prasad,

Department of ENT and Head and Neck Surgery,

Command Hospital (EC), Alipore Road,

Kolkata 700027, West Bengal, India

Email: bipin_rupa@rediffmail.com

Dr B K Prasad takes responsibility for the integrity of the content of the paper

Competing interests: None declared 